\title{
An exploratory qualitative study on the effects of intimate partner violence in lower socio-economic status women : findings from an urban slum cohort
}

\author{
Afshaan Peerzada ${ }^{1}$, Avinash De Sousa $^{2}$ \\ ${ }^{1}$ Post graduate student, Department of Psychology, R.D. National College, Mumbai. \\ ${ }^{2}$ Research Associate, Department of Psychiatry, Lokmanya Tilak Municipal Medical College, Mumbai. \\ E-mail - avinashdes888@gmail.com
}

\begin{abstract}
Background: Intimate partner violence (IPV) is a global phenomenon and is a public health problem having fundamental consequences on women's physical, mental and reproductive health. There is scarcity of literature on how poverty and the intimate partner violence can have a link and how IPV is so rampant in poor, slum areas.

Methodology: This study is set occurring in low social economic status women in the slum areas of Bharatnagar, Mumbai. This is a exploratory qualitative research with an aim to assess the experiences of abuse among battered women, the impact and repercussions it may have on their health, explore the reasons for which women belonging to low socio economic status continue to stay in abusive relations. Qualitative approach was used to interview five women in the age group of 18-38 years from the populous slums of Bharatnagar, selected on the basis of purposive sampling from the BMMA (NGO). Semi structured interviews were employed to collect data.

Results: During analysis the findings were discussed under the following identified themes of violence, neglect, spousal control, economic vulnerability and also suggested that abuse by an intimate partner negatively affects women's physical/ psychological health. Fear of retaliation, societal reasons, respect for parents, concern for children and economic dependence were the themes describing the woman's will to stay inspite of abuse.

Conclusion: IPV has different correlates in lower socio-economic strata women and needs further exploration across different populations.
\end{abstract}

Keywords: intimate partner violence, women, qualitative, post traumatic disorder, socio-economic status.

(Paper received $-25^{\text {th }}$ July 2016, Peer review completed $-20^{\text {th }}$ August 2016, Accepted $-6^{\text {th }}$ September 2016)

\section{INTRODUCTION}

WHO describes Intimate Partner Violence (IPV) as "any behaviour within an intimate relationship that causes physical, psychological or sexual harm to those in the relationship" [1]. The most common perception of violence and latently refers to the fact that people often don't see or perceive violence until it becomes visible. Therefore, often it is not only the witnesses of violence who do not understand it is happening in front of their eyes - in fact, those experiencing the violence themselves do not realize they are victims. The violence that women are subjected to is most commonly is interpersonal violence committed by an intimate partner as the women are often emotionally involved with and economically dependent on those who victimize them has major implications for both the dynamics of abuse and the approaches to dealing with it [2]. In the National Family Health Survey (NFHS-3), the prevalence of violence against married women in various slum areas in India was reported to be between 23-62\%. Violence against 
women also has a substantial impact on health resulting in more ill health and premature death among women of reproductive age than any other risk factor, including high blood pressure, obesity, psychosis, manic-depression, anxiety, death and accounting for $40-60 \%$ of female homicides \& maternal mortality in India, Bangladesh, and the United States [4].

The claim is often made that domestic violence affects individuals in all social classes. But the data and research done in this arena have had samples that have low incomes or are living in poverty [5]. Poverty and associated stress are key contributors to intimate partner violence. Since poverty is inherently stressful, it has been argued that intimate partner violence may result from stress and that poorer men have fewer resources to reduce stress. Although it is certainly the case that middle class and affluent families do experience domestic violence, studies consistently indicate that as the financial status of a family increases, the likelihood of domestic violence decreases. Poor women are more vulnerable to homelessness, are also at greater risk of domestic violence. Women with household incomes of less than 5000 are 7 times as likely as women with household incomes over 55,000 to experience domestic violence [6].

Slum environment is characterized by low socio-economic status, unhealthy living conditions, and lack of basic services. These aspects play a role in women's vulnerability to abuse and their inability to break free from abusive relationships. Features of the environment (e.g. poor housing) create situations of distress, dissatisfaction, stress and rage, which increase the likelihood of intimate partner violence [7]. Abused women are routinely restricted in the way they can gain access to information and services, take part in public life, and receive emotional support from friends and relatives, unable to properly look after themselves and their children and can have host of different health outcomes, both immediate and longterm including ill-health with regard to physical functioning, psychological well-being depression; suicide attempts; chronic pain syndromes; psychosomatic disorders; physical injury; gastrointestinal disorders; irritable bowel syndrome and a variety of reproductive health consequences [8].

The purpose of the study is to understand the various forms of abuse which women are subjected to by the husband, to assess the impact/ effects of Intimate partner violence on their health and explore \& determine the reasons for women staying in an abusive relationship.

\section{Theoretical basis for IPV}

Battered Women Syndrome was developed after Martin Seligman's classical Learned Helplessness Theory [9] where a abused woman has learned to behave helplessly even though there is an opportunity to escape from an unpleasant situation. However, this does not imply abused women are helpless at all. Rather, abused women may choose to stay in abusive relationships but give up the belief that they are able to escape from their abusers because of chronic suffering. This criteria is a subcategory in the post traumatic stress disorder having symptoms of re-experiencing the battering even though it is not reoccurring,Avoiding the psychological impact of abuse by avoiding personal emotions, family and Friends, and social activities, Hyper arousal or hyper vigilance, Disrupted interpersonal relationships, Somatic problems, Sexuality and intimacy issues.

Lenore Walker [10] was among the first to explore the etiology of depression in IPV victims. She developed 'Cycle of Abuse' to describe the behavioural pattern of abusers and the responses of abused women to the violence having three stages tension building phase characterized by the abuser becoming jealous, angry and the victim using calming strategies with him. The second stage was acting out phase which characterized by the injury and abuse of the victim making her feel scared. The third stage is the honeymoon phase wherein the abuser becomes apologetic and this change in behaviour in him is shortlived and the cycle begins again. The researcher aimed to see his study and the research question through this cycle that abused women undergo.

The ecological framework is based on evidence that no single factor can explain why some people or groups are at higher risk of interpersonal violence, while others are more protected from it. This framework views interpersonal violence as the outcome of interaction among many factors at four levelsthe individual, the relationship, the community, and the societal. At the individual level, personal history and biological factors influence how individuals behave and increase their likelihood of becoming a victim or a perpetrator of violence. Personal relationships such as family, friends, intimate partners and peers may influence the risks of becoming a victim or perpetrator of violence. Community context in which social 
relationships occur, such as schools, neighbourhoods and workplaces, also influence violence. Societal factors influence whether violence is encouraged or inhibited by economic and social policies, the availability of weapons, and social and cultural norms [11].

A traumatic bonding theory explains the dynamics of domestic violence and explains why victims stay with their abuser or return to the relationship. It states that "strong emotional connections develop between the victim and the perpetrator during the abusive relationship. These emotional ties develop due to the imbalance of power between the batterer as the abuser gains more power, the abused feels worse about himself/herself and is less able to protect themselves and is less competent. The abused person therefore becomes increasingly dependent on the abuser. This seemingly paradoxical response has also been seen abused children, incest victims, and pimp-procured prostitutes and is specifically linked to intimate partner four precursors were necessary for the development of Stockholm syndrome i.e. perceived threat to survival, perceived kindness, isolation and perceived inability to escape [12-13].

\section{METHODOLOGY}

The researcher used the narrative approach because it captures the emotion of the moment described, rendering the event active rather than passive, infused with the latent meaning being communicated by the teller. The results of qualitative research are descriptive rather than predictive.

\section{Study setting: Bharatnagar Location: Islampura, Bandra east, Mumbai}

The area of Bharatnagar started to get inhabited in 1975. It was a khadi (low) area. There are only around 3 lakh hutments and 64 chawls. In addition there are 12 plots. The Navpada and Bharat Nagar community is almost predominantly Muslim community mostly the Ansari and Qureshi belonging to the OBC caste within the Muslim community with very few Hindu and Christian families. The Ghazbazar section of Navpada consists of very poor families whose sources of income are informal and unorganized. Lack of education has been one of the hurdles in the way of the development of the Muslim community. Women are involved in doing domestic work and earn about Rs.3000/- per month. Some women work from home and do stitching work and earn around Rs.1200/- per month. Women also burn tobacco and make mishri (tobacco application). Most women are home makers. Men work as taxi and auto drivers and earn around Rs. 5000/- monthly. Around half of the working men are involved in garment business and in mutton shop and earn around Rs.6500/- monthly. Men are also into hawking and petty sales and earn around Rs. 3000/- monthly. The community civic amenities are extremely poor.

\section{Participants}

The participants were 5 married women aged 18-38 years who were living with their husbands at the time of the interview. The length of the marriages was in the range of 3-17 years. These women were included in this research through the organization called BMMA which solves cases of poor battered/ abused/ divorced women. Purposive sampling was used to develop the sample. The criteria for participant selection were: having experience of intimate partner violence in a marital relationship; being fluent in the Hindi/ English language; belonging to lower economic status, being Indian, being married, being at least 18 years of age, having a willingness to participate in the study, and giving informed written consent. Exclusion criteria were being pregnant and less than six months postpartum, suffering from psychosis. The participants' educational levels was $10^{\text {th }}$ pass/fail residing in kaccha slums or one room houses in Bharat Nagar. One out of these five was a house wife the rest of them were either working as a tailor, seller of raddi goods, social worker, unskilled jobs to earn daily bread. All these women initiated to go out and work because of financial crises, husband not giving them money and basic needs unfulfilled. Almost half of the participants reported an inappropriate economic status earning lesser than six thousand a month and 60 thousand a year. All women had children. 
Table 1 - Participants of the study

\begin{tabular}{|lclllll|} 
Participants & Age & No of years married & Employment & Education & $\begin{array}{l}\text { No of } \\
\text { children }\end{array}$ & $\begin{array}{l}\text { Economic } \\
\text { status }\end{array}$ \\
\hline 1 & 32 & 17 years & Social worker & $10^{\text {th }}$ pass & 2 & Poor \\
2 & 22 & 2 years & Shop & $10^{\text {th }}$ pass & 1 & Poor \\
3 & 33 & 7 years & Unemployed & $10^{\text {th }}$ pass & 1 & Poor \\
4 & 22 & 3 years & Maid & $10^{\text {th }}$ fail & 1 & Poor \\
5 & 24 & 5 years & Mehendi work & $10^{\text {th }}$ pass & 1 & Poor \\
\hline
\end{tabular}

\section{Interview Procedures}

Semi-structured interviews were done to collect data. Interviews began with a general question such as "describe your married life?" Then participants were asked if they had been hurt abuse in their married life by their husbands, if so, they were asked to talk about it; they were encouraged to share their experiences and understanding of the being abused. If necessary, their responses were further investigated using probing questions such as "What do you mean by this statement?" or "Can you explain it in detail?"

A total of 5 interviews were conducted. Interviews lasted from 45 minutes to 95 minutes. In-depth semistructured interviews were held with at least five women who were known to have been abused by their partners or former partners. Audiotapes were transcribed by the researcher and then was examined and coded. Clusters of similar experiences were made a theme and were explained with their own quotes.

\section{Ethical Considerations}

Researcher took into consideration ethical issues for participants and explained the purpose of the study, obtained informed written consent (appendix) and ensured information privacy and confidentiality. We also explained to the participants that they have right to withdraw from the study at any time, to check and request a copy of their records and transcripts, and choose the time, place and duration of the interview.

\section{RESULTS}

Each participant had a unique experience with violence. Victims interviewed in this study reportedly mentioned to be facing not only physical blows but also were psychologically harmed. It also uncovered the various health consequences that the women reportedly face cause of IPV. Through the analysis, 3 master themes emerged and were broken down into subcategories.

\section{Abuse}

1.1 Violence, 1.2 Spousal control, 1.3 Neglect, 1.4 Neglect during pregnancy, 1.5 Economic vulnerability, 1.6 Mental/emotional abuse, 1.7 Lack of social support.

\section{Impact of Intimate partner violence}

2.1 Physiological impact, 2.2 Psychological impact

\section{Reasons to stay in relationship}

3.1. Economic dependence, 3.2. Societal pressures/ respect for parents, 3.3. Hoping for change

\section{Theme 1a : Violence}

Four out of five women reported to have succumbed to different forms of physical violence such as slapping, beating, throwing things at her, pulling her hair, banging her head against the wall, pushing her out of the house, injuring her body, dragging her on the road. Case $\mathrm{K}$ is describing the violence meted out to her.

"Haata paayi hoti hai, itna maarta hai ki khoon nikaal deta hai. Dusre ghar ke log bhi bolte hain maar isko chodna na nahin". 
Case A narrated an incident wherein she was hit by her spouse for a trivial reason of not boarding the train on time

"Station par mera sar deewar main maarna chaalu kardiya.khamba hota hai na lokhand ka main station par behosh ho gayi thi. Just because train 5 :10 waali train miss hogayi thi."

The respondents reported that the spouse resorted to severe beating causing pain, injuries such as cuts, swelling, fractures, abrasions, stitches, visits to hospitals, disruption of normal work. Case $\mathrm{K}$ mentioned about the injury when the interviewer asked about the fresh marks on her wrist.

"Ye nishaan bangles ke hai, unhone kaach ke bangles ko gusse main daba diya tha, aur kaach ekdum andar chala gaya tha.Kaanch chubkar andar nahin ghujaaye tab tak dabaakar rakha mera haath."

The women also reported the means via which they were hit. Some were hit by objects like knife, glass, bamboo, stick, pushed from the bed with the leg.

"Haath se, lakdi leke, Kabhi chura (knife) kabhi lakdi (stick) kabhi unke haath bhi kaafi hota hai. Kabhi gusse main dhakka dete hain.Mujhe shayad aisi koi jagah nahin jahan nahin haath uthaaye hai."

\subsection{Economic vulnerability}

All the respondents were economically vulnerable, uneducated, and financially dependent on their spouses. Burden fell on women to support, inability of man to gather himself and work again, no social security, no insurance, no medical insurance, weak labour law, women also enter informal sector with low income because uneducated. Prostitution is also one option that women think of in extreme vulnerable situation, when unable to arrange fees of children. Case $\mathrm{K}$ was so helpless during the times when her husband was in the hospital with a broken limb and the responsibilities fell on her head. She recalls that time when she thought of getting into prostitution.

"Wohi haal main sasur ka intekaal aur khaane ke laale pad gaye the. Do devar ki bhi zimmedari mere sar par aa gayi thi. Ek saath bahut zimmedaariyan sar par aagayi thi. Maine bure bure khyaal soch li thi ki main prostitution main ghus jaun"

Women when trying to work outside and earn daily bread is seen as loose, sexually promiscuous and is spied upon.

"Tu kaam par thodi gayi thi tu toh tere yaar ke saath maraane gayi thi."

Saving is also difficult as man in suspicion checks pass books, bank accounts, searches clothes, dabbas in the kitchen for money saved. Suspicion that she is hiding money from him.

"Main Khud ke paise save bhi nai kar sakti hoon. meri gair mawjudgi (absence) main woh mere paise dhundte hai har jagah, cupboard khaali karte hai. Mujhe ye sabse buri aadat lagti hai. Kya main mere paise bhi nai bacha sakti hoon.?

\subsection{Neglect and deprivation}

All the 5 women reported being disturbed when they were left to be on their own emotionally physically. Neglect makes the women feel unloved, unwanted and uncared for. It also means neglecting the basic necessities, callousness, insensitivity and at times also to teach the woman a lesson. Emotional neglect was the most common form could happen in one or more of the following areas: attention, affection, support, understanding, companionship and communication.

Case $\mathrm{K}$ states how unloved and segregated she and her children felt.

"Ghar ke pakaane se, kharcha paani tak sab main karti hoon. Koi cheez unko maloom nahin bachon ki fees kya hai bacchon ke function kab hain. kaunse class main. Kabhi zimmedari ka ehsaas nahin"

Case $\mathrm{C}$ states how she is deprived of time from her husband. She states that how she longs and misses talking to him.

"Kaam se aaye toh baat bhi nahin kare aayee khaana khaaye tv dekhe aur so gaye. Kuch bhi baat nahin kare and na mujhe puche ki mera din kaise gaya."

\subsection{Neglect during pregnancy}

Neglect was also seen when the women expects utmost care. During pregnancy 3/5 women reported that their husband ill treated them during pregnancy, didn't provide her with nutritious food, negligent in terms of taking her to the hospital, beating and kicking her during pregnancy.

Case $\mathrm{C}$ states that when she was pregnant her husband was absconding. 
"Bacche ke time par jo support hona chahiye woh unhone nahin diye. Jab mera aakhri mahina tha toh puchte hain ki baccha uska hai ki nahin. Usne toh khabar tak nahin li meri pregnancy ki. Main aapko kya batao mujhe kaisa mehsoos hua tha"

Case A recalls the most painful time of her life when she lost her baby because of the negligence of her in laws and her husband.

"5th mahine chalu hua toh baccha nahin bacha. Doctor ne bole ki ye laaparvaahi (negligence) ke wajah se hua hai. Aapko pehle ise hospital laana chahiye tha. Toh maine wahan abortion ki. Mera husband nahin diya fees.Usne computer main sonography main dekhe ki baccha pura khatam ho chukka tha. Mere husband ne bhi ek baar bhi nahin pucha ki main kaisi hoon. Ye cheez ke liye mujhe bahut bura laga."

\subsection{Spousal control/ mental torture}

Four out of 5 women reported to be scolded and abused brutally by their husbands making her feel diffident and embarrassed. Scolding were accompanied by condescending language, deriding her, making snide comments and hurling abuses.

"Bolta hain mujhe badla le raha hoon. Bikhra ke rakhunga, rakhdakar rakhunga, aisa bolta hai"

The respondents also reported an incident when their respective spouses stopped them to use a mobile or communicated with her dear and near ones. They were reported to be isolating her to teach the wife a lesson.

Case B: "Ekdum akele. Jab ammi log milna aate the mujhe milne nahin dete the Mujhe dusre goan le jaate the..Phone bhi nahin karne de te the. Sim card tod dete the. Phone phod dete the."

Case $\mathrm{S}$ recalls her experience when she was badly abused by her husband when she decided to have a bath in the evening.

"Raat mein tu nahaai kaise? ek thappad mare phirr subah uthke maare, bole raat mein nahaati hai kya? Kya problem hai, maine nahaai aise hi,garmi ho rahi thi to main dar gayi thi, maar rahe the bohot."

The respondent also reported how the spouses at times became overly suspicious and started to pass comments on the wife's character and sexuality.

"Mujhe mooh dhone bhi dar lagta tha. Mooh dhokar jaati thi toh mujhe puchte the ki kahan ja rahi hai kyun jaa rahi hain. Main jahan jaati thi wahan main mori (washroom) main bhi nahin jaa sakti thi kyunki unko lagta hai ki galat kaam karne gayi hoon kisi ke saath."

\subsection{Sex with others/ infidelity}

It is an important cause of distress for women was the men's extramarital relationships. 3 out of 5 women knew or suspected that their husbands were having affairs with other women, they couldn't stop commenting or expressing anger towards it.

"Mere behen se tak buri nigah rakhta tha. Mere mard ne Ek ladke ko bol "khaapikar chodna hai aur man bhar jaaye toh mere pass chod dena (use and throw).Mera jo aadmi hain uska relation uska uski phuppi aur cousin ke saath hai. Sab kuch(sex) kar lete hai dono."

\subsection{Sexual relations}

The women could never express their desire to have sex. It was only done when the men wanted it. Asking for it shows the women in a bad light.

"Nahin main toh aisa bol hi nahin paa sakti. Aisa bolenge toh bolenge ki baahar jaati aur tereko khujli mithaani (sexual satisfaction) hain. Ek dum rough language vaapar lenge. Main aisa toh soch bhi nahin sakti hoon bolna toh door ki baat hain.

Another theme seen with respect to these women was that the men were quite aggressive during sex and the women succumbed to a lot of pain.

"Main nahin bolti thi isliye mujhe maarte the. Zabardasti mujhse relation rakhte the.Apna ko nikalta hain na (precum) mere aang(body) par hi daal dete the. Royungi ya dard hoga toh bolenge ki ye toh tera naatak hai."

\section{Reasons to stay in the relationship}

"Sabse jhagda karaa diya hai usne Ki mera koi aasra (support) na ho. Aur sabko ye lage ki main ye rishte main fail hogi. 


\subsection{Economic dependence}

Domestic violence stresses that economic dependency barricaded women in relationships.

"Mera koi support nahin hain. Ek raat rukne ka aasra nahin hai kahin bhi chaahe mummy ka ghar ho ya bhai ka. Bolte hai sab hai ki mere ghar main aakar raho lekin ache se nai rakhte hai. Isliye main inke paas rehti hoon kyunki mere sar par koi chat (roof) nahin hai na koi support hai'.

\subsection{Hoping for change}

The women expected that the abuser be given a chance and there is still scope for remorse and change in the behaviour.

"Unke saath akele rehna hai. Mujhe lagta hai woh sudhar jaayenge. Woh shayad frustrated hai. Shaadi nibhaani hai aur padegi"

\subsection{Societal reasons/ for the respect of the parents}

The women thought it's an institution that needs to be respected and adhered to. And she breaking it would bring wrath to her, family and would be labelled as a failed woman who can't even salvage her marriage.

"Sudharna hai bas inko. Itne saalon se nibhaa rahi hoon is intezaar main ki sudhar jaayenge. Sab bolte hai ki shaadi karke aaenge toh waai rehne ka kuch bHi hojaae. Mere bacchon aur ma baap ki izzat ke liye ruki hoon".

\subsection{Lack of social support}

As these women married of their choice, married young, had a lot of siblings and belonging to very poor families they couldn't go back to their place of origin. Their parents weren't open minded enough to accept her and had lack of resources to fund her and her child so the woman decided to endure.

"Mera koi support nahin hain. Isliye main inke paas rehti hoon kyunki mere sar par koi chat nahin hai na koi support hai".

\section{Impact on health due to IPV: Mental health, Physical health and reproductive health}

\subsection{Mental health}

After the thematic analysis the researcher was enlightened to see the far reaching effects of IPV on women's psychological wellbeing. These mentioned symtoms were not present before the marriage or before the escalation of abuse.

Case $\mathrm{C}$ states that post the abuse and marriage her mental wellbeing and sleep has gone for a toss.

"Ina tension aata hain ki mujhe lagta hain main depression main chali jaungi. Main pure din is cheez ke bare main sochti rehti hoon. Mujhe aur kuch nahin sujhta hai. Mujhe kisi par bharosa hi nahin hain, aisa lagta hai sab mujhe dhokha denge."

Case A states how she has changed and how her health deteoriarated.

"Ye sab main soch sochkar paagal ho rahi thi. To matlab main poori paagal ho gayi thi. spasm ka problem hai aur jo mera nas phat taa hai na sar mein itnna dard hota haiki poori nas (nerve) phat ti hai aur meko naak se blood aata hai.Saans lene mein problem na ha wo time pe jabhi stress leti hu tabhi hota hai. Heart beats heart mein to aisa lagta hai bas abhi dam nikal jaaega itna zyada pain hone lagta hai.Ghabrahat hoti hai aur aisa rone jaisa lagta hai itna rona aata hai ki bas khatam hone walli hu aawaz hi nahi niklegi kalse bas, 2- 3 ghante tak ho jaaata hai Mere dimaag mein chaalta rehta hai jis bhi cheez se main guzri hoon.

\section{1a Suicidality/ self harm}

The researcher found that amongst 5 women who were interviewed all had suicidal ideations and thoughts. Out of five there were four people who have committed suicidal attempts. The methods discussed in the interviews by women were gulping down kerosene, camphor, acid, ratkill. Suicidal thoughts were expressed in terms of "Abhi zindagi ka kya phayda", "mujhe yahan se bhaag jaana hai kahin door" etc.

"Suicide soche kya puchte ho maine kar bhi di thi.2 baar ki hoon. Ek baar Maine ghaaslet pi li thi. Aur dusri baar maine zeher pee li thi. Zulm bardasht nahin tha. Bahut maarte the mujhe. 


\subsection{Physiological health}

IPV has long term health consequences for battered women it can manifest in terms poor health status, injuries, fear, stress, chronic pain (headaches, back pain), fainting, feelings of being choked, palpitations, shivering, gastrointestinal problems i.e. loss of appetite, functional gastrointestinal disorders in terms of (chronic irritable bowel syndrome), cardiac symptoms like hypertension, blood pressure, chest pain, hyper vigilance.

Case $C$ expresses the physiological changes that took place after her marriage.

"Blood pressure ki bimaari ho gayi isse shaadi karne ke baad. Blood pressure shaadi ke baad hua. Thyroid, allergy, BP shaadi ke baad hua. Ye aadmi ke saath rehne ke baad hua. Pregnancy main bhi main ekdum dukhi rehti thi aur ye sab goliyan khaati thi. Do do BP ki goliyan khaati hoon. Doctor bolta hain iska dhyaan rakho kyunki iski nas phat jaayegi bahut stress leti hoon main

\subsection{Reproductive health}

Women who live with violent partners have a difficult time protecting themselves from coerced sex, inability of the women to use contraceptives. Violence during pregnancy is also involved associated with Miscarriage, Premature labour and birth, fetal injury, vaginal infections, low birth weight, unable to feed the child etc.

Case A narrates her traumatic experience of losing her child due to the negligence of her husband and mother in law. Despite repeated complains of pain in uterus and weakness and doctors advice for immediate admission to the hospital she wasn't taken to the hospital

"Usne boli 99 percent pas (septic) hogaya hai. Pehle laana chahiye tha Doctor ne kaha ab iski haalat nahin hai ghar jaane ki. Phir bhi Meri saans ne boli mujhe mere bête se puchna padega. Itna lightly liye mere husband aur in laws ne ki mujhe $5^{\text {th }}$ mahine main baccha girwaana pada nelgligence ki wajah se.."

\section{ANALYSIS OF FINDINGS}

This work is unique in that it is one of the few studies that has provided an opportunity for slum women in an urban slum to describe and relate their own interpretation of their experiences with intimate partner violence. All the participants defined their intimate relationships with an imbalance of power control violence, devoid of warmth, affection, love and fulfilment of needs. All the women who were interviewed reported that their relationship is fearful and most of their lives were threatened by their partner. The themes sought with respect to the experiences of abused were violence, neglect, spousal control, sexual relation, infidelity and neglect during pregnancy, economic vulnerability.

The women reportedly also saw an increase of beating which grew more pronounced with the use of weapons, causing injury etc. The women were very disappointed with the way they were not given attention and neglected. At times this neglect had dire consequences resulted in poor health and abortion during pregnancies. Their sexual relations also had the element of power and control. The researcher gets a glimpse of how patriarchy seeps in the bedroom in terms of being forceful during sex, throwing the discharge on the women's face if she declines to have sex, hit her while having sex etc. It also somewhere reinforces that men believe that women can't ask for sex and if they work out that means they are necessarily sleeping around. Mental abuse saw a variety of noteworthy behaviours to exert power and supremacy over the females from controlling behaviours, suspicious behaviours, not allowing her to take basic decisions etc. The most striking ones were isolation from parents and outer world to limit her coping and breaking her defences. Not allowing meeting her parents by emotional blackmail, a woman can't have a bath when she wants to or use the loo out of the fear that she would be labelled as a loose woman when she returns home, to asking for sex at the demise of a woman's father. Also the biggest blow to these women was the fact the husband was involved with some other lady. Case $\mathrm{K}$ had broken down and expressed "Main apne aapko khoobsurat nahin samajhti, agar khoobsurat hoti toh woh kisi aur ke paas kyun jaate"?

The study results indicated that participants have experienced physical, sexual, and emotional overt violence. This classification is in accordance with the findings of other qualitative studies on women's experiences with intimate partner violence and is consistent with existing definitions of intimate partner 
violence. The findings have demonstrated the women are mentally conditioned to accept violence against them as the way of life.

\section{Factors of the women that made these women susceptible to abuse}

The researcher used "ecological framework" developed by Heise distinguishes risk factors at four levels: the individual, the relationship, the community and the structural level [11] to explain why the women were so susceptible to violence. The women who were interviewed were educated till school married young, financially dependent, no equipped to be absorbed in the formal sector, limited access to community resources, medical care, lack of fruitful childhood experiences, conservatism, low confidence, lacked social support i.e. tangible resources, support network and perceived support. Reportedly even their primary social support being parents were also very punitive and unsupportive in terms of not supporting her when she was dealing from abuse.

Violence is often deployed as a tactic in relationship conflict as well as being an expression of frustration or anger. Marital instability - ie, a partner considering leaving the marriage-is a time of especial risk of violence. Research found that societies that had community sanctions against violence, including moral pressure from neighbours to intervene in place and where women had access to shelter or family support had the lowest levels of intimate partner and sexual violence which was clearly not the case with the women who were interviewed.

Also poverty and economic vulnerability does play a role in reinforcing violence as the men understand the helplessness of the women and her inability to look after herself and her children financially. While intimate partner and sexual violence do cut across all socio-economic groups, several studies found women living in poverty to be disproportionately affected [14], the findings of being vulnerable and not supported by the family and community can be seen in theme "reasons to live in the abusive relationship".

These women are viewed as society as loose women if they work outside their homes to earn, most women cited reasons as societal factors that stop them from not leaving the relationship throws light on how society exerts pressure on the women to continue the relationship against all odds to fit in the category of a good woman. Also breakage of relationship signals her failure as a wife stating how that will impact her sisters [15]. Thus, the interplay of all these elements predisposes a woman to risk and abuse.

The third objective of the research was to explore the consequences and the repercussions of battering. Battering is a significant direct and indirect factor for various physical health problems frequently seen in health care settings. The consequences extend to not only injuries, bruises, abrasions, cuts, welts, stitches but also to mental/ psychological wellbeing and physical health \& functioning and reproductive health [16].

The five women who were interviewed stated various changes in their psychological wellbeing namely, displaying trust issues, sleep deprivation, depressive rumination, uneasiness, tenseness and anxiety, crying spells, intense fear, shivers when recalling an abusive memory, emotional numbing, loss of appetite, reduced weight, psychosomatic pains, palpitations, cold flashes, shortness of breath, lack of self worth, self mutilation (suicide), hypervigilance and loss of interest. There is a link between women's experiences of domestic violence and adverse mental health effects, demonstrate the substantial serious psychological harm strongly and consistently associated with abuse by male partners. [17]. Despite these health associations, over half of physically abused women (55 to 95\%) reported that they had never sought help from formal services or from people in positions of authority [18].

The women who were interviewed showed these symptoms in their narratives which fit in the category of major depressive disorder, persistent depressive disorder, PTSD and phobias but lack of standardized testing and assessment was a deterrent in diagnosing them.

Four out of five women were battered which is a risk factor for various physical health problems. These effects manifest in terms of poor health status, poor quality of life and frequent visits to the health care centres, injuries ranging from cuts, bruises, abrasions to permanent disability. Women resportedly mentioned "nas phat jaayegi", "phasli tut gayi", sar par stitches aaye hai, wrist pe bangdi dabaayi gayi hai, kaan phat gaya etc. The physiological health consequences werent just limited to injuries but also medical ailments having longstanding effects. Women mentioned to be having chronic pain syndromes (case $\mathrm{S}$ mentioning severe debilitating headaches), back pain, neck pain. 
In addition, women who experienced violence by a partner were more likely to report poor general health and greater problems with walking and carrying out daily activities, pain, memory loss, dizziness, and vaginal discharge in the 4 weeks before the interview. This study corresponds with a previous research which states that abused women were more likely to experience emotional distress and to have considered or attempted suicide. An association between recent ill health and lifetime experience of violence suggests that physical and mental effects may last long after the violence has ended [19].

In the theme of reasons to live in the abusive relation the women cited various reasons to live in the relation despite the odds. The reasons cited are fear of retaliation, economic dependence, societal pressures, loneliness, concern for children, hoping for the husband to reform etc. Their resistance towards the idea of leaving the relationship can be explained by the bettered syndrome has its basis in the theory of learned helplessness [9] where these women learnt to behave helplessly even though there is an opportunity to escape from an unpleasant situation because of chronic longstanding suffering. These women dealt with the abuse through their own strategies to distract themselves from psychological suffering by suppressing their emotions, with time they become numb, cynical, pessimistic give up the hope which makes them feel down, discouraged and may eventually feel that there is nothing that they can do about it. Discussions with the respondents indicated an environment wherein violence was considered as the woman's fate and the husband's right. This acceptance then leaves no room for action taken by them. Their responses clearly indicate their helplessness, economic dependence, concern for losing their children.

Another theory which can explain the women's desire to stay in an abusive relationship is the Traumatic bonding theory. Dutton and Painter [20] explain how repeat victimisation of the women as well as a number of risk factors such as abuse, anger, aggression combine to produce an extreme insecure attachment style between the spouses i.e. the abuser and the abused.

\section{Implications and Suggestions for Future Studies}

Violence against women is a complex social problem, and our knowledge on how to address it is evolving. Tackling the problem requires coordinated action that engages communities and many different sectors including health, education, and justice to challenge the inequities and social norms that give rise to violence and to provide emotional and physical support for victims. Early intervention, particularly targeting children who witness violence or are abused, is a promising yet underdeveloped area for action. Developing curricula for children and young people to learn emotional and social skills, including nonviolent methods of conflict resolution, could be an important contribution to violence prevention. Support services for abused women and programs to sensitize legal systems are also needed.

\section{Methodological considerations}

It should be reiterated that the women who participated in this portion of the study were self-identified as being victims of intimate partner violence. Thus, the findings represent a profile of women who had been resistant in leaving their abusive relationship. Despite a passage of time since the abuse, these women seemed to have recalled their experiences vividly. Also, because a limited number of individuals were interviewed using qualitative methodology, the findings of this investigation may not be generalized to a larger audience. More research is needed to determine if the findings in this study are generalized to the larger population of women belonging to low economic status. Still, qualitative methodology allows for reflection on the participants' insights and through the women's own words better defines the problem and the possible solution. The study didn't focus use any self inventory or assessment to help diagnose the symptoms The sample contained women showing varied duration of abuse which wasn't studied or focussed on and the severity of the effects were not compared. (for eg. Case K endured 17 years of abuse whereas Case B endured 4-5 years of abuse).

\section{Conclusion}

Through this study we obtain knowledge of how low economic status women in an urban slum, view, experience intimate partner violence and will provide researchers and practitioners with an understanding of tackling this issue. This study provides some information regarding the experiences of these women, its 
impact and their reasons to stay. Further exploration of the influence of religion, attachment styles of the partners, ghetto culture on the manifestation of intimate partner violence is needed. This study outlines the risk factors but the protective and preventive factors need to be explored. Enhancing help-seeking behavior and increasing the quality of social support for victims in this community require the development of effective educational and intervention methods. Any such endeavours should involve a broad-based method tailored specifically for the poor women to raise awareness, increase knowledge, and enhance empathy for victims of intimate partner violence, devise intervention strategies, making health and psychiatric services more accessible.

\section{REFERENCES}

1. Krug EG, Mercy JA, Dahlberg LL, Zwi AB. The world report on violence and health. Lancet 2002;360(9339):1083-8.

2. Schewe PA. Preventing violence in relationships: Interventions across the life span. American Psychological Association; 2002.

3. Gupta K, Arnold F, Lhungdim H. Health and living conditions in eight Indian cities. National Family Health Survey (NFHS-3) India 2005-06.

4. García-Moreno C. Global and regional estimates of violence against women: prevalence and health effects of intimate partner violence and non-partner sexual violence. World Health Organization; 2013.

5. Lim BH, Adams LA, Lilly MM. Self-worth as a mediator between attachment and posttraumatic stress in interpersonal trauma. Journal of interpersonal violence. 2012;10:0886260511431440.

6. Mercy JA, Krug EG, Dahlberg LL, Zwi AB. Violence and health: the United States in a global perspective. Am J Pub Health 2003;93(2):256-61.

7. Campbell JC, Webster D, Koziol-McLain J, Block C, Campbell D, Curry MA, Gary F, Glass N, McFarlane J, Sachs C, Sharps P. Risk factors for femicide in abusive relationships: Results from a multisite case control study. Am J Pub Health 2003;93(7):1089-97.

8. Weaver TL, Clum GA. Psychological distress associated with interpersonal violence: A meta-analysis. Clin Psychol Rev 1995;15(2):115-40.

9. Abramson LY, Seligman ME, Teasdale JD. Learned helplessness in humans: critique and reformulation. J Abnorm Psychol 1978;87(1):49-60.

10. McGuigan WM, Middlemiss W. Sexual Abuse in Childhood and Interpersonal Violence in Adulthood A Cumulative Impact on Depressive Symptoms in Women. J Interpers Viol 2005;20(10):1271-87.

11. Almgren G. The Ecological Context of Interpersonal Violence From Culture to Collective Efficacy. J Interpers Viol 2005;20(2):218-24.

12. Becker-Blease KA, Freyd JJ. Beyond PTSD An Evolving Relationship Between Trauma Theory and Family Violence Research. J Interpers Viol 2005;20(4):403-11.

13. Namnyak M, Tufton N, Szekely R, Toal M, Worboys S, Sampson EL. 'Stockholm syndrome': psychiatric diagnosis or urban myth?. Acta Psychiatr Scand 2008;117(1):4-11.

14. Yalch MM, Lannert BK, Hopwood CJ, Levendosky AA. Interpersonal style moderates the effect of dating violence on symptoms of anxiety and depression. J Interpers Viol 2013;28(16):3171-85.

15. McHugo GJ, Caspi Y, Kammerer N, Mazelis R, Jackson E, Russell L, Clark C, Liebschutz J, Kimerling R. The assessment of trauma history in women with co-occurring substance abuse and mental disorders and a history of interpersonal violence. J Behav Health Serv Res 2005;32(2):113-27.

16. Dutton MA, Green BL, Kaltman SI, Roesch DM, Zeffiro TA, Krause ED. Intimate partner violence, PTSD, and adverse health outcomes. J Interpers Viol 2006;21(7):955-68.

17. Bradley RG, Follingstad DR. Group therapy for incarcerated women who experienced interpersonal violence: A pilot study. J Traum Stress 2003;16(4):337-40.

18. Hedtke KA, Ruggiero KJ, Fitzgerald MM, Zinzow HM, Saunders BE, Resnick HS, Kilpatrick DG. A longitudinal investigation of interpersonal violence in relation to mental health and substance use. J Consult Clin Psychol 2008;76(4):633-9.

\footnotetext{
Acknowledgements - Nil

Source of Funding - Nil

Conflict of Interest - Nil
} 